\title{
Prenatal metal exposure, cord blood DNA methylation and persistence in childhood: an epigenome-wide association study of 12 metals
}

\author{
Anne K. Bozack ${ }^{1}$ (), Sheryl L. Rifas-Shiman ${ }^{2}$, Brent A. Coull ${ }^{3}$, Andrea A. Baccarelli ${ }^{4}$, Robert O. Wright ${ }^{5}$, \\ Chitra Amarasiriwardena ${ }^{5}$, Diane R. Gold ${ }^{6,7,8}$, Emily Oken ${ }^{2}$, Marie-France Hivert ${ }^{2,9}$ and Andres Cardenas ${ }^{1,10^{*}}$
}

\begin{abstract}
Background: Prenatal exposure to essential and non-essential metals impacts birth and child health, including fetal growth and neurodevelopment. DNA methylation (DNAm) may be involved in pathways linking prenatal metal exposure and health. In the Project Viva cohort, we analyzed the extent to which metals ( $\mathrm{As}, \mathrm{Ba}, \mathrm{Cd}, \mathrm{Cr}, \mathrm{Cs}, \mathrm{Cu}, \mathrm{Hg}$, $\mathrm{Mg}, \mathrm{Mn}, \mathrm{Pb}$, Se, and $\mathrm{Zn}$ ) measured in maternal erythrocytes were associated with differentially methylated positions (DMPs) and regions (DMRs) in cord blood and tested if associations persisted in blood collected in mid-childhood. We measured metal concentrations in first-trimester maternal erythrocytes, and DNAm in cord blood $(N=361)$ and midchildhood blood ( $N=333,6-10$ years) with the Illumina HumanMethylation450 BeadChip. For each metal individually, we tested for DMPs using linear models (considered significant at FDR $<0.05$ ), and for DMRs using comb-p (Sidak $p<0.05)$. Covariates included biologically relevant variables and estimated cell-type composition. We also performed sex-stratified analyses.
\end{abstract}

Results: Pb was associated with decreased methylation of cg20608990 (CASP8) (FDR =0.04), and Mn was associated with increased methylation of $\mathrm{cg} 02042823(A 2 B P 1)$ in cord blood $\left(F D R=9.73 \times 10^{-6}\right)$. Both associations remained significant but attenuated in blood DNAm collected at mid-childhood $(p<0.01)$. Two and nine Mn-associated DMPs were identified in male and female infants, respectively ( $F D R<0.05$ ), with two and six persisting in mid-childhood $(p<0.05)$. All metals except Ba and $\mathrm{Pb}$ were associated with $\geq 1$ DMR among all infants (Sidak $p<0.05$ ). Overlapping DMRs annotated to genes in the human leukocyte antigen (HLA) region were identified for $\mathrm{Cr}, \mathrm{Cs}, \mathrm{Cu}, \mathrm{Hg}$, Mg, and $\mathrm{Mn}$.

Conclusions: Prenatal metal exposure is associated with DNAm, including DMRs annotated to genes involved in neurodevelopment. Future research is needed to determine if DNAm partially explains the relationship between prenatal metal exposures and health outcomes.

Keywords: DNA methylation, EWAS, Manganese, Metals, Prenatal exposure

\footnotetext{
*Correspondence: andres.cardenas@berkeley.edu

${ }^{1}$ Division of Environmental Health Sciences, School of Public Health,

University of California Berkeley, 2121 Berkeley Way, Room 5302, Berkeley, CA 94720, USA

Full list of author information is available at the end of the article
}

\section{Background}

Essential trace metals are critical for fetal development [1]. Copper $(\mathrm{Cu})$ [2], magnesium $(\mathrm{Mg})$ [3], manganese (Mn) [4], selenium (Se) [5], and zinc ( $\mathrm{Zn}$ ) [6] are involved in many biological processes and serve as cofactors or allosteric components to enzymes. Low maternal status original author(s) and the source, provide a link to the Creative Commons licence, and indicate if changes were made. The images or other third party material in this article are included in the article's Creative Commons licence, unless indicated otherwise in a credit line to the material. If material is not included in the article's Creative Commons licence and your intended use is not permitted by statutory regulation or exceeds the permitted use, you will need to obtain permission directly from the copyright holder. To view a copy of this licence, visit http://creativecommons.org/licenses/by/4.0/. The Creative Commons Public Domain Dedication waiver (http://creativeco mmons.org/publicdomain/zero/1.0/) applies to the data made available in this article, unless otherwise stated in a credit line to the data. 
of essential metals has been associated with adverse birth outcomes including preterm birth [7], decreased birth weight, and growth restriction [4], as well as infant and child health outcomes including neurodevelopment, cognitive function [8-10], and increased risk for infections [10].

Environmental exposure to harmful heavy metals and metalloids, collectively referred to here as "metals," from natural and anthropogenic sources is also a public health concern. The toxicity of some heavy metals can lead to adverse health outcomes through various biological mechanisms including oxidative stress, disruption of cell membrane potential and homeostasis, and competitive binding to proteins $[11,12]$. Higher levels of nonessential metals including arsenic (As), cadmium (Cd), and lead $(\mathrm{Pb})$ have been associated with risk of low birth weight [13-15]. In addition, As, Cd, mercury $(\mathrm{Hg})$, and $\mathrm{Pb}$ are potent neurotoxicants, and prenatal exposure to these metals has been associated with decreased measures of neurodevelopment and cognitive function in children [16-19]. Essential metals may also have nonlinear associations with child health. For example, maternal Mn has been shown to have an inverse U-shaped relationship with neurodevelopment in infants, with low and high levels associated with poor mental and psychomotor development [8]. Additionally, sex-specific associations for metals and health, including metal uptake and retention, have been reported, highlighting the need to study sex-specific associations [20, 21]. Specifically, sex-specific associations have been reported with early-pregnancy maternal metal concentrations and birth outcomes in the Project Viva cohort [22].

Changes in epigenetic markers may be involved in the biological pathways, or serve as biomarkers, relating metal exposure to infant and child health. Embryonic development is a time of rapid epigenetic reprogramming, which may impact health outcomes later in life. As proposed by the developmental origins of health and disease $(\mathrm{DOHaD})$ hypothesis [23], pre- and postnatal exposures that occur during critical developmental periods may affect disease phenotypes through epigenetic mechanisms including DNA methylation (DNAm) reprogramming [24]. Prenatal maternal exposure to a range of environmental contaminants including some metals has been associated with alterations in global and locus-specific DNAm [25].

For selected metals, there is ample evidence of epigenetic dysregulation. For example, multiple epigenomewide association studies (EWAS) of prenatal As exposure have been conducted, including populations with both low [26, 27] and high exposure levels [28-30]; however, a common epigenetic signature of prenatal As exposure has not been identified, but rather multiple cohort-specific signals. Fewer EWAS of other prenatal metal exposures have been conducted. For Pb, two EWAS have identified varying signatures across populations. An EWAS prenatal $\mathrm{Pb}$ exposure and cord blood DNAm conducted in a cohort in Mexico did not identify significant associations between $\mathrm{Pb}$ and locus-specific DNAm [31]. However, an EWAS conducted among mother-infant pairs in the United States (US)-based Project Viva cohort $(N=268)$ identified four CpGs associated with second-trimester maternal red blood cell (RBC) $\mathrm{Pb}$ concentrations among infants overall, with $38 \mathrm{CpGs}$ among female and two among male infants in sex-stratified analyses $(F D R<0.05)$ [32]. Also, within Project Viva, second-trimester maternal RBC Hg concentrations were associated with methylation of one CpG among infants overall and of one $\mathrm{CpG}$ among males $\left(N=321 ; p_{\text {Bonferroni }}<0.05\right)$ [33].

Considering the limited epidemiological research on associations between prenatal metal exposures and epigenetic dysregulation, in this study we investigate the extent to which prenatal metals measured in first-trimester maternal RBCs are associated with DNAm profiles in cord blood and compare associations across metals. Leveraging data and samples from Project Viva, a pre-birth cohort with relatively low levels of metal exposures, we analyzed associations between prenatal exposure to 12 metals [As, barium (Ba), Cd, chromium ( $\mathrm{Cr}$ ), cesium (Cs), $\mathrm{Cu}, \mathrm{Hg}, \mathrm{Mg}, \mathrm{Mn}, \mathrm{Pb}, \mathrm{Se}, \mathrm{Zn}]$ and differentially methylated positions (DMPs) and regions (DMRs) in cord blood. The current research expands upon previous analyses conducted in Project Viva by investigating multiple metals measured during the first trimester, reflecting exposure during embryonic, rather than fetal, development. We also investigated sex-specific associations and persistence of observed associations in mid-childhood.

\section{Results}

\section{Participant characteristics}

DNAm data were available for 361 (Additional file 1: Figure S1) and 333 mother-infant pairs at birth and in mid-childhood, respectively, and a total of 189 motherinfant pairs had both cord blood and mid-childhood DNAm data. Characteristics of mother-infant pairs and maternal blood metal concentrations are provided in Table 1. Among participants with cord blood DNAm data, the median (IQR) maternal age at enrollment was $32.4(29.7,35.9)$ years. The majority of mothers were college graduates and had household incomes $>\$ 70,000$ per year $(70.6 \%$ and $60.4 \%$, respectively). Approximately half of infants were female (46.8\%), 70.4\% were White, and $11.4 \%$ were Black. Spearman correlations between metals are presented in Additional file 1: Figure S2. The greatest correlations were observed between $\mathrm{Cu}$ and $\mathrm{Zn}(r=0.56)$, As and $\mathrm{Hg}(r=0.50), \mathrm{Cu}$ and $\mathrm{Mg}(r=0.45)$, and $\mathrm{Mg}$ and 
Table 1 Characteristics of Project Viva mother-infant pairs with cord blood and mid-childhood samples

\begin{tabular}{|c|c|c|c|c|}
\hline & \multicolumn{2}{|c|}{ Cord blood $(N=361)$} & \multicolumn{2}{|c|}{ Mid-childhood $(N=333)^{a}$} \\
\hline & $N$ or median & $\%$ or IQR & $N$ or median & $\%$ or IQR \\
\hline \multicolumn{5}{|l|}{ Maternal characteristics } \\
\hline Age at enrollment (years), median (IQR) & 32.4 & $(29.7,35.9)$ & 32.9 & $(29.7,36.2)$ \\
\hline College graduate & 255 & $70.6 \%$ & 234 & $70.3 \%$ \\
\hline Smoking during pregnancy & 41 & $11.4 \%$ & 38 & $11.4 \%$ \\
\hline Annual household income $>\$ 70,000$ & 218 & $60.4 \%$ & 206 & $61.9 \%$ \\
\hline Nulliparous & 177 & $49.0 \%$ & 150 & $45.0 \%$ \\
\hline Prenatal BMI, median (IQR) & 23.5 & $(21.3,27.2)$ & 23.5 & $(21.5,26.6)$ \\
\hline \multicolumn{5}{|l|}{ Red blood cell concentration (ng/g), median (IQR) } \\
\hline As & 0.86 & $(0.46,1.5)$ & 0.81 & $(0.44,1.64)$ \\
\hline $\mathrm{Ba}$ & 3.15 & $(2.06,5.95)$ & 3.10 & $(1.96,5.57)$ \\
\hline $\mathrm{Cd}$ & 0.39 & $(0.27,0.56)$ & 0.40 & $(0.27,0.55)$ \\
\hline $\mathrm{Cr}$ & 1.31 & $(0.86,1.91)$ & 1.37 & $(0.87,2.16)$ \\
\hline Cs & 2.53 & $(2.02,3.14)$ & 2.48 & $(1.94,3.14)$ \\
\hline $\mathrm{Cu}$ & 562 & $(517,620)$ & 560 & $(513.0,619.0)$ \\
\hline $\mathrm{Hg}^{\mathrm{b}}$ & 3.19 & $(1.69,6.68)$ & 3.26 & $(1.85 .5 .89)$ \\
\hline $\mathrm{Mg}$ & 41,500 & $(37,100,46,400)$ & 41,000 & $(36,600,46,000)$ \\
\hline $\mathrm{Mn}$ & 15.80 & $(13.10,19.70)$ & 15.70 & $(12.80,19.80)$ \\
\hline $\mathrm{Pb}$ & 18.10 & $(13.90,23.80)$ & 18.00 & $(14.00,19.00)$ \\
\hline Se & 249 & $(222,279)$ & 247 & $(222,274)$ \\
\hline $\mathrm{Zn}$ & 10,300 & $(9,380,11,600)$ & 10,300 & $(9,280,11,500)$ \\
\hline \multicolumn{5}{|l|}{ Infant characteristics } \\
\hline Female & 169 & $46.8 \%$ & 158 & $47.4 \%$ \\
\hline Gestational age (weeks), median (IQR) & 40 & $(39.0,40.9)$ & 39.9 & $(38.9,40.6)$ \\
\hline Birth weight z-score & 0.19 & $(-0.35,0.90)$ & 0.24 & $(-0.35,0.97)$ \\
\hline \multicolumn{5}{|l|}{ Race/ethnicity } \\
\hline White & 254 & $70.4 \%$ & 221 & $66.4 \%$ \\
\hline Black & 41 & $11.4 \%$ & 52 & $15.6 \%$ \\
\hline Hispanic & 20 & $5.5 \%$ & 17 & $5.1 \%$ \\
\hline Asian & 8 & $2.2 \%$ & 9 & $2.7 \%$ \\
\hline More than one race or other & 38 & $10.5 \%$ & 34 & $10.2 \%$ \\
\hline Age at mid-childhood blood draw (years), median (IQR) & - & - & 7.66 & $(7.38,8.25)$ \\
\hline
\end{tabular}

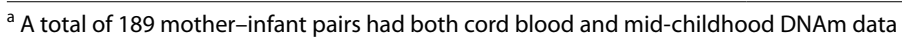

${ }^{\text {b }}$ Cord blood: $N=358$; mid-childhood: $N=326$; data are complete for all other variables

Se $(r=0.44)(p<0.05)$. There were no significant differences in baseline characteristics or prenatal maternal blood metal concentrations between mother-infant pairs with cord blood or mid-childhood DNAm data $(p>0.10)$.

In linear models adjusted for infant sex, race, gestational age, maternal age, pre-pregnancy BMI, education, household income, and smoking, prenatal $\mathrm{Cu}$ exposure was associated with $\mathrm{CD} 4+\mathrm{T}$ cell proportions estimated using the Houseman regression calibration method. For every doubling of $\mathrm{Cu}$ concentration, there was an increase of $3.25 \%$ in the proportion of estimated CD $4+\mathrm{T}$ cells $(p=0.037)$ (Additional file 1: Table S1). There was a trend toward positive associations between $\mathrm{Cd}$ and
$\mathrm{CD} 4+\mathrm{T}$ cells and between $\mathrm{Hg}$ and monocytes, although these associations did not achieve statistical significance ( $B=0.63, p=0.05$ and $B=0.23, p=0.05$, respectively).

\section{Differentially methylated positions}

Manhattan and Q-Q plots for each metal in fully adjusted models for cord blood DNAm are shown in Fig. 1 and Additional file 1: Figure S3, respectively; $\lambda$ values are presented in Additional file 1: Table S2. Full results of EWAS for each metal are available on the study's GitHub repository (https://github.com/annebozack/viva_DNAm_metals) and Open Science Framework site (https://osf.io/ jf5yt/). Among infants overall, prenatal exposure to $\mathrm{Mn}$ 


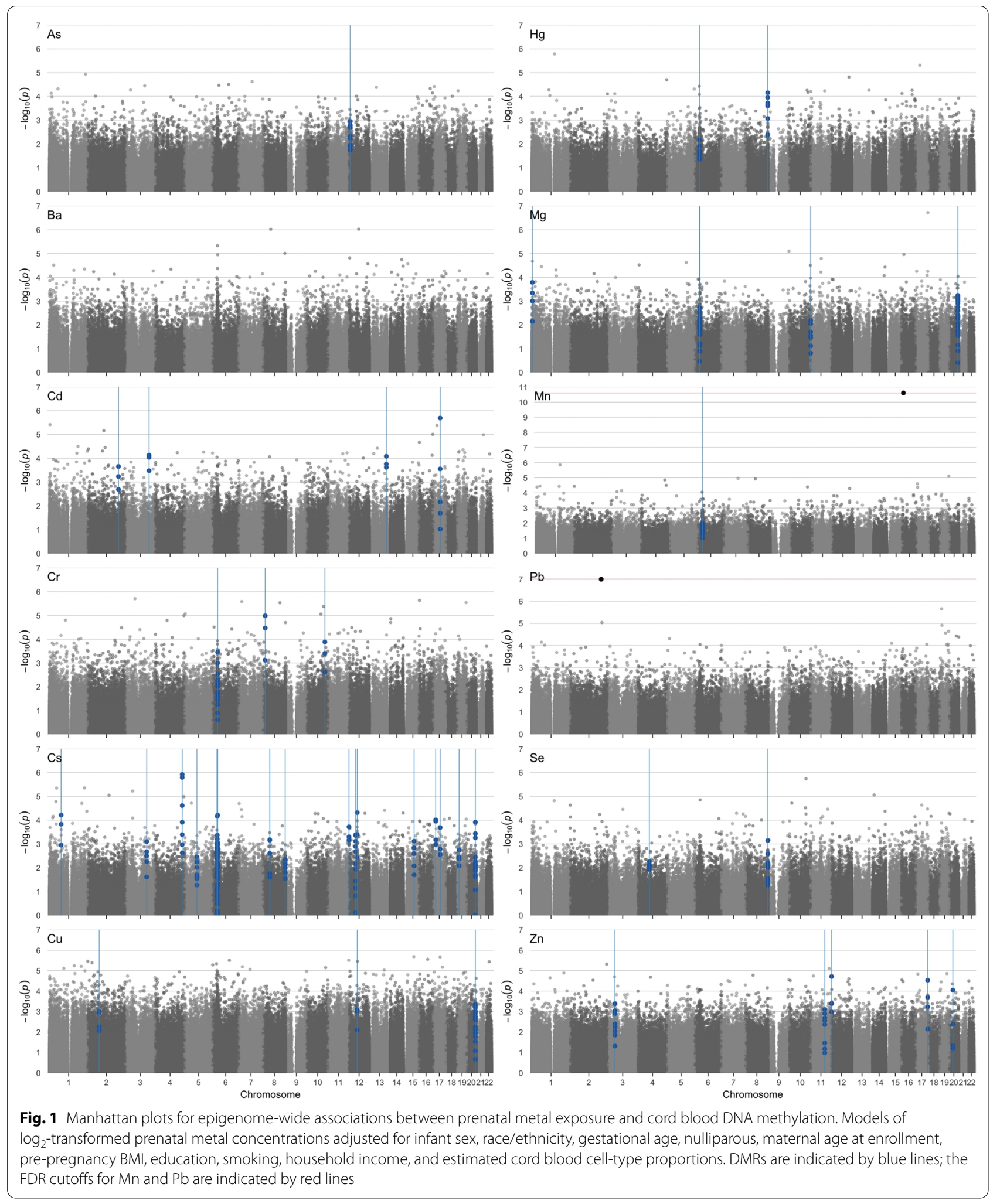


was associated with greater methylation of $\mathrm{cg} 02042823$, annotated to $A 2 B P 1$ (Table 2). Each doubling of prenatal $\mathrm{Mn}$ concentrations was associated with $2.65 \%$ greater methylation (95\% CI: $2.07,3.23 ; p=2.47 \times 10^{-11}$; $\left.\mathrm{FDR}=9.7327 \times 10^{-6}\right)$ at this $\mathrm{CpG}$. Pb exposure was associated with 3.10\% lower DNAm at cg20608990, annotated to CASP8, with each doubling of $\mathrm{Pb}$ concentrations (95\% CI: $-4.22,-1.97, p=1.02 \times 10^{-7}, \mathrm{FDR}=0.04$ ) (Table 2). No DMPs achieved statistical significance in analyses of other metal exposures among infants overall (FDR > 0.05), or in sensitivity analyses for As and $\mathrm{Hg}$ adjusting for maternal fish intake.

In stratified analyses, $\mathrm{Mn}$ exposure was associated with nine DMPs among females [cg00954161 (LRRC47), $\quad$ cg11161853 (SUCLG2), $\quad$ cg23903787 (LRPAP1), cg19908812 (NPY1R), cg26462130 (MAD1L1), cg08904630 (intergenic), cg22799518 (RBMS2), cg01744822 (intergenic), and cg15712310 (intergenic)] and two DMPs among males [cg03763518 (C1orf54) and cg02042823 (A2BP1)] (FDR <0.05; Table 2). In linear models testing for effect modification by sex, significant $\mathrm{Mn} \times$ sex interaction terms were observed for cg00954161, cg11161853, cg23903787, cg19908812, cg26462130, cg08904630, cg22799518, cg01744822, cg15712310, and cg03763518 $(p<0.05)$. There was not significant $\mathrm{Mn} \times$ sex interaction for cg02042823 (A2BP1) $(p=0.06)$, although the association between prenatal $\mathrm{Mn}$ and DNAm of cg02042823 was nominally significant among females ( $B$ for each doubling of $\mathrm{Mn}=1.08 \%$; $p=0.014$ ) but met statistical significance after adjustment for multiple comparisons among males $(B$ for each doubling of $\mathrm{Mn}=3.40 \%$; FDR $=1.10 \times 10^{-4}$ ). No DMPs were statistically significant in sex-stratified analyses for other metal exposures (FDR $>0.05$ ), or for As and $\mathrm{Hg}$ adjusting for maternal fish intake.

Persistence of cord blood DMPs associated with prenatal $\mathrm{Mn}$ and $\mathrm{Pb}$ exposure was tested in blood collected in mid-childhood (Table 2). Mn remained persistently associated with greater methylation of cg02042823 $(A 2 B P 1)$ among all infants $(B=0.75 ; p=0.01)$ and for DMPs found in males [cg03763518 (C1orf54): $B=-$ 3.03; $p=1.74 \times 10^{-4}$ and cg02042823 (A2BP1): $B=1.82$; $\left.p=2.34 \times 10^{-4}\right]$. Of the nine Mn-associated DMPs among females, seven were nominally significant in mid-childhood (cg00954161, cg23903787, cg26462130, cg08904630, cg22799518, cg01744822, and cg15712310; $p<0.05)$. Among these CpGs, the direction of association was consistent between the two outcome time points with the exception of cg22799518 (RBMS2; cord blood $B=2.03, p=2.03 \times 10^{-7}$; mid-childhood $B=-0.20$, $p=0.004)$. The DMP negatively associated with first-trimester Pb among infants overall (cg20608990; CASP8) remained significantly associated in mid-childhood
$(B=-1.56 ; p=0.008)$. Mid-childhood results were consistent when restricting analyses to only children included in the cord blood EWAS $(N=189)$ except for cg22799518 among females, which failed to achieve nominal significance $(p=0.07)$.

We compared our results to previous EWAS of second-trimester maternal $\mathrm{RBC} \mathrm{Pb}$ (Wu et al. 2017) and $\mathrm{Hg}$ (Cardenas et al. 2017) conducted in Project Viva. Among four CpGs associated with second-trimester $\mathrm{Pb}$ among infants overall, one was nominally associated with first-trimester $\mathrm{Pb}$ in our study (cg22112000: $B=-0.09 \%, p=0.046$ ), and among 38 CpGs associated with second-trimester $\mathrm{Pb}$ among females, four were nominally associated with first-trimester $\mathrm{Pb}$ in our study (cg17971003: annotated to $S L N, B=0.90 \%, p=0.044$; cg05959994: TFDP1, $B=-0.31 \%, \quad p=2.30 \times 10^{-4}$; cg04571282: KIAA1267, $B=-0.34 \%, p=1.11 \times 10^{-4}$; cg11610754: TMEM59L, $B=0.07 \%, p=0.039$ ) (Additional file 1: Table S3). The direction of association between $\mathrm{Pb}$ and $\mathrm{DNAm}$ was consistent between analyses of first- and second-trimester concentrations. Neither of the two CpGs associated with second-trimester $\mathrm{Pb}$ among males replicated in our study. One CpG was previously associated with second-trimester $\mathrm{Hg}$ among infants overall (cg13340705, WBP11P1), and one CpG (cg13416866, TOR4A) and one DMR (chr7:94,953,65394,954,202, PON1) was associated with second-trimester $\mathrm{Hg}$ among males (Cardenas et al. 2017). Although the CpG associated with $\mathrm{Hg}$ among infants overall did not replicate in our study, among males, cg13416866 had a nominally significant association with first-trimester $\mathrm{Hg}$ and consistent direction of association $(B=0.51 \%$; $p=0.028$ ) (Additional file 1: Table S3). Consistent with second-trimester $\mathrm{Hg}$ analyses, all $\mathrm{CpGs}$ in the region chr7:94,953,653-94,954,202 had a negative direction of association among males in our study of first-trimester $\mathrm{Hg}$, although only one was nominally associated with $\mathrm{Hg}$ (cg04871131, $B=-0.60 ; p=0.026)$ and four had nominal $p$ values $<0.10(\operatorname{cg} 01874867: B=-1.54 ; p=0.061$; cg17330251: $B=-1.55 ; p=0.051 ; \operatorname{cg} 19678392: B=-$ 1.07, $p=0.062 ; \operatorname{cg} 07404485: B=-0.76, p=0.099)$.

\section{Differentially methylated regions}

The number of DMRs identified in cord blood for each metal among infants overall and stratified by sex is listed in Table 3 (Sidak $p<0.05$ ) and is shown in the Manhattan plots in Fig. 1 (noted by bolded individual CpGs within the region). For each DMR, the chromosomal coordinates, gene, probes, probe effect sizes, and $p$ values in linear analyses (limma) are provided in Additional file 2: Spreadsheets 1-12. In summary, at least one DMR was identified among infants overall for all metals with the exception of $\mathrm{Ba}$ and $\mathrm{Pb}$. Cs was associated with the 


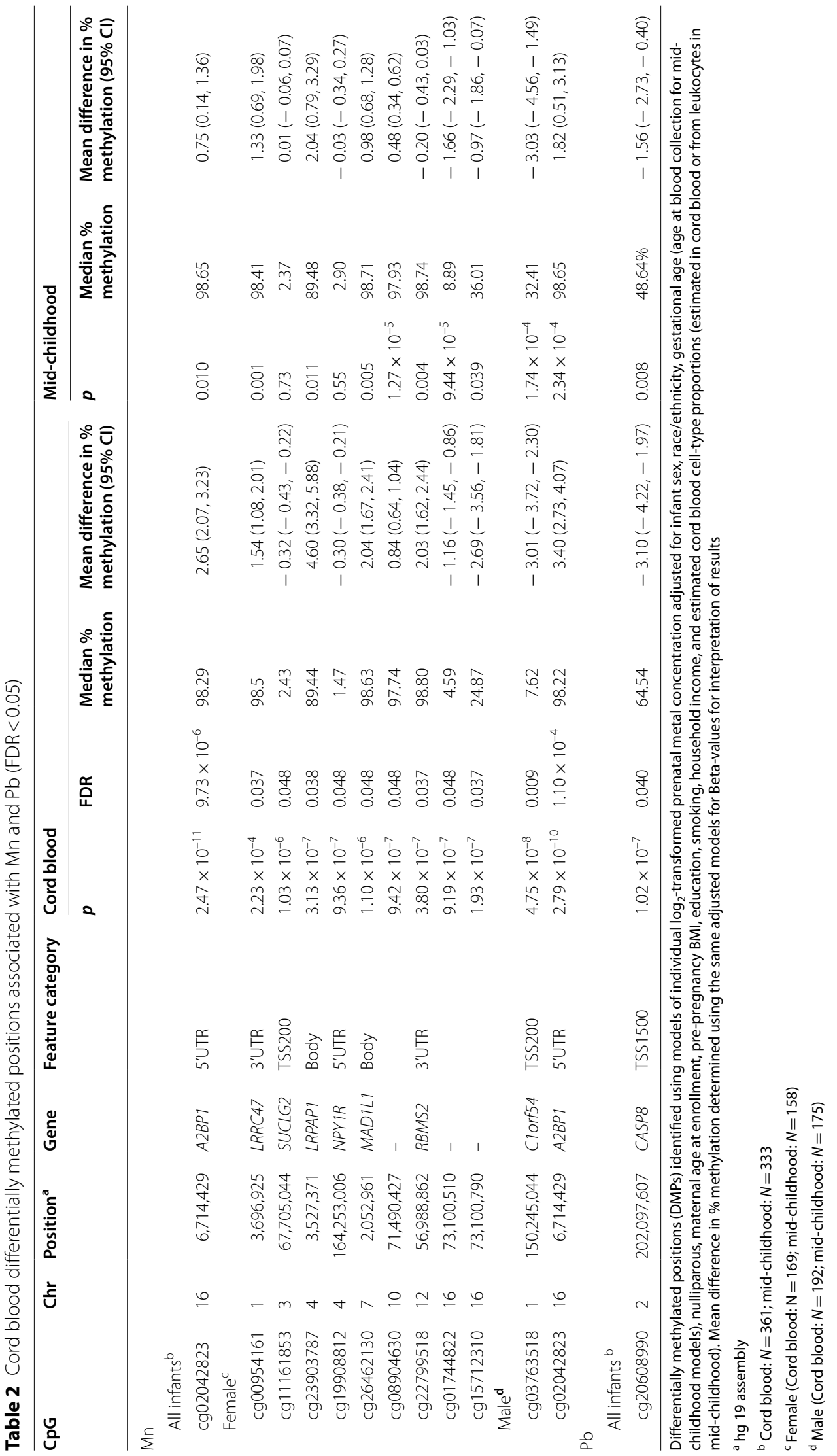


Table 3 Summary of cord blood differentially methylated regions (Sidak $p<0.05$ ) associated with individual metals

\begin{tabular}{|c|c|c|c|c|c|c|}
\hline & All infant & $\mathrm{s}(N=361)$ & Female $(\Lambda$ & $V=169)$ & Male $(N=$ & 192) \\
\hline & $\begin{array}{l}\text { Number } \\
\text { of DMRs }\end{array}$ & Genes & $\begin{array}{l}\text { Number } \\
\text { of DMRs }\end{array}$ & Genes & $\begin{array}{l}\text { Number } \\
\text { of DMRs }\end{array}$ & Genes \\
\hline As & 1 & LOC144571 & 2 & CAT & 3 & LDHC; LOC144571; OXT \\
\hline $\mathrm{Ba}$ & 0 & & 2 & GSDMD; VENTX & 2 & DDX60; LOC619207 \\
\hline $\mathrm{Cd}$ & 4 & HOXB7 & 2 & HOXA11 & 3 & HIST1HIA; SLC17A9 \\
\hline $\mathrm{Cr}$ & 3 & B3GALT4; DLC1; TCF7L2 & 2 & $D L C 1$ & 0 & \\
\hline Cs & 18 & $\begin{array}{l}\text { ZBTB38; CMYA5; VARS2; GTF2H4; PPP1R2P1; TAPBP; LYNX1; } \\
\text { RAD52; PUS7L; IRAK4; ZNF385A; MIR548H4; NOX5; RAII; } \\
\text { SKAP1; SLC44A2; GNAS; GNASAS }\end{array}$ & 3 & STMN1; GOPC; IRAK4; PUS7L & 14 & $\begin{array}{l}\text { ZBTB38; VARS2; } \\
\text { GTF2H4; LRRC27; } \\
\text { WSCD2; MIR548H4; } \\
\text { NOX5; RAII }\end{array}$ \\
\hline $\mathrm{Cu}$ & 3 & INO8OB; HNRPA1L-2; HNRNPA1; CBX5; GNAS; GNASAS & 1 & GNAS; GNASAS & 6 & $\begin{array}{l}\text { NTNG1; PRSS50; } \\
\text { HAPLN1; PPP1R2P1; } \\
\text { HNRPA1L-2; HNRNPA1; } \\
\text { CBX5 }\end{array}$ \\
\hline $\mathrm{Hg}^{\mathrm{a}}$ & 2 & RNF39; LYNX1 & 0 & & 3 & RNF39; LYNX1 \\
\hline Mg & 5 & FLJ42875; RNF39; TNXB; B4GALNT4; GNAS; GNASAS & 3 & CRIP2; WFIKKN2; GNAS; GNASAS & 1 & AURKC \\
\hline $\mathrm{Mn}$ & 1 & $T N X B$ & 7 & $\begin{array}{l}\text { SUCLG2; HLTF; AGPAT4; CARD11; } \\
\text { HOXA4; OXGR1 }\end{array}$ & 3 & TTC23; BLCAP; NNAT \\
\hline $\mathrm{Pb}$ & 0 & & 0 & & 2 & SEMA5B \\
\hline $\mathrm{Se}$ & 2 & PF4; GSDMD & 3 & GSDMD;CYP1A1;ADAMTSL5 & 1 & AURKC \\
\hline $\mathrm{Zn}$ & 5 & COL7A1; MTNR1B; CACNA2D4; FSCN2; LOC284798 & 0 & & 3 & TMEM88B; MCC \\
\hline
\end{tabular}

Differentially methylated regions (DMRs) identified using models of individual log 2 -transformed prenatal metal concentrations adjusted for infant sex, race/ethnicity, gestational age, nulliparous, maternal age at enrollment, pre-pregnancy BMI, education, smoking, household income, and estimated cord blood cell-type proportions all infants: $N=358$; female: $N=167$; male: $N=191$

largest number of DMRs among infants overall $(N=18)$. Multiple DMRs associated with $\mathrm{Cr}, \mathrm{Cs}, \mathrm{Cu}, \mathrm{Hg}, \mathrm{Mg}$, and $\mathrm{Mn}$ were located in the human leukocyte antigen (HLA) region of chromosome 6 (Fig. 2a-h).

We assessed the overlap among DMRs identified for each metal (Table 4). Three DMRs were identified as associated with more than one metal in analyses of infants overall for $\mathrm{Hg}$ and $\mathrm{Mg}$ (chr6: RNF39, Fig. 2a), $\mathrm{Mg}$ and $\mathrm{Mn}$ (chr6: TNXB, Fig. $2 \mathrm{~b}$ ), and $\mathrm{Cs}, \mathrm{Cu}$, and $\mathrm{Mg}$ (chr20: GNAS, GNASAS).

Results from Gene Ontology (GO) enrichment analysis of DMRs are summarized in Table 5; complete results and differentially methylated genes within GO terms are included in Additional file 2: Spreadsheet 13. We identified nominally significant GO terms with an overrepresentation of differentially methylated genes associated with $\mathrm{Cr}(N=18), \mathrm{Cs}(N=20)$, $\mathrm{Cu}(N=17)$, Se $(N=41)$, and $\mathrm{Zn}(N=18) \quad(p<0.05)$; no terms remained significant after FDR adjustment. The majority of GO terms (87\%) belonged to the biological process domain. Three GO terms were identified for multiple metals, although differentially methylated genes within GO terms differed between metals. Common GO terms were: cellular response to DNA damage stimulus [GO:00069741, associated with Cs (differentially methylated: ZBTB38, ZNF385A,
GTF2H4, RAD52) and $\mathrm{Cu}(C B X 5, I N O 80 B)]$, response to stress [GO:0006950, Cu (CBX5, GNAS, HNRNPA1, $I N O 80 B)$ and Se (PF4, GSDMD)], and cellular response to stress [GO:0033554; Cs (ZBTB38, ZNF385A, GTF2H4, IRAK4, RAD52, NOX5) and $\mathrm{Cu}(C B X 5$, HNRNPA1, INO80B)]. In addition, related terms were identified for multiple metals. For example, regulation of apoptotic process (GO:0042981), regulation of programmed cell death (GO:0043067), and regulation of cell death (GO:0010941) were identified for $\mathrm{Cr}$, whereas cell death (GO:0008219) and programmed cell death (GO:0012501) were identified for Se.

In sex-stratified analysis, at least one DMR was identified in all analyses among females with the exception of $\mathrm{Hg}, \mathrm{Pb}$, and $\mathrm{Zn}$, and in all analyses among males with the exception of $\mathrm{Cr}$ (Table 3, Sidak $p<0.05$ ). DMRs located in the HLA region were also identified among males (for Cs: chr6: intergenic and GTF2H4; for Hg: RNF39; Fig. 2ad). Although the majority of these DMRs were specific to sex-stratified analyses, within metals, we did observe overlap between DMRs identified in analyses of infants overall and stratified by sex (Additional file 1: Table S4). Two sets of overlapping DMRs were associated with multiple metals only in analyses restricted to males: Cs and Hg (chr6: 31,650,735-31,651,361, Fig. 2e) and Mg and Se (chr19: AURKC). 


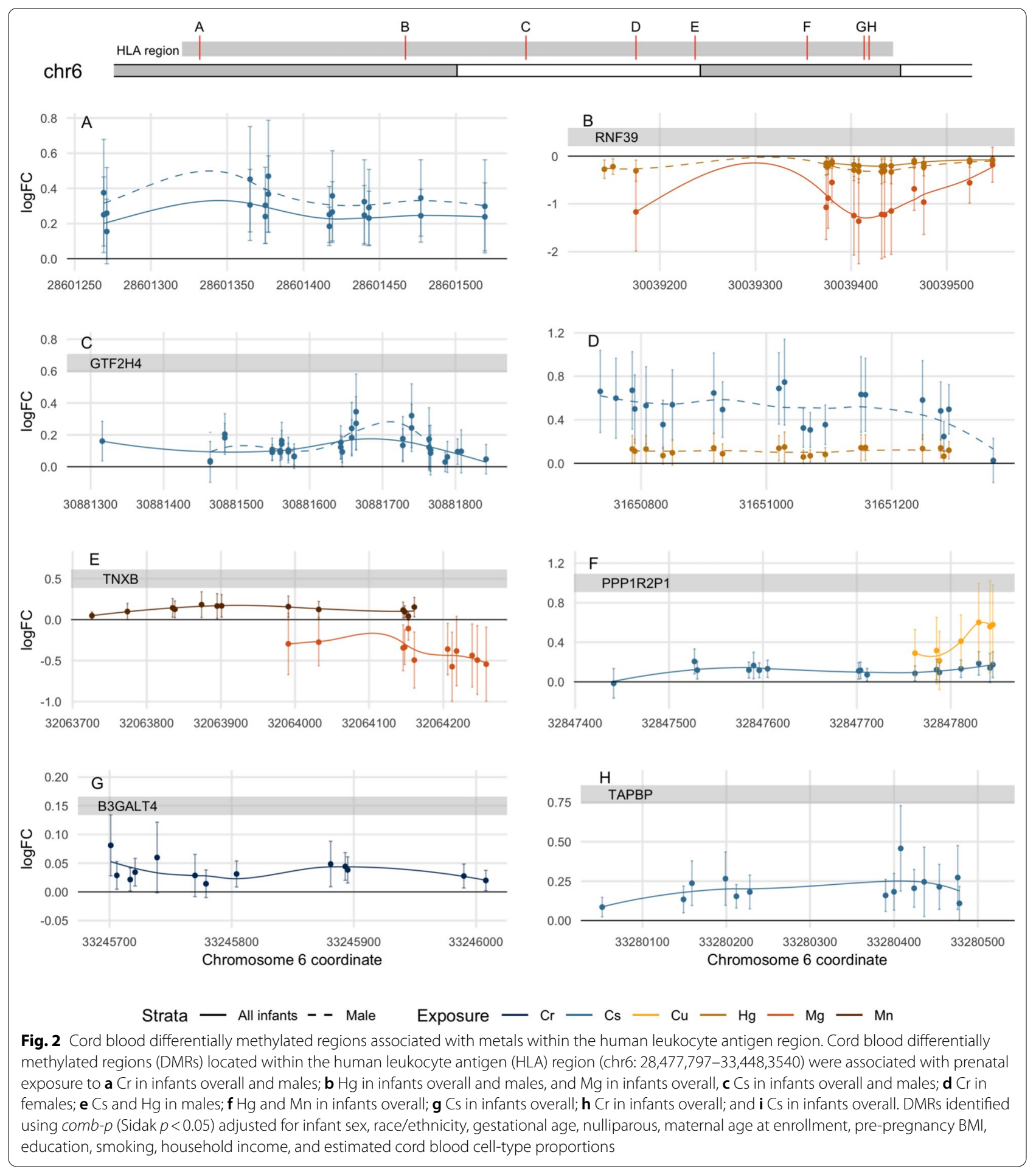

To assess persistence of associations within DMRs in mid-childhood, we compared the probe effect sizes and $p$ values from DMP analyses within each region between cord blood and mid-childhood (Additional file 2: Spreadsheets 1-12). Among infants overall, four
DMRs contained $100 \%$ of probes that were nominally significant in mid-childhood $(p<0.05)$, associated with Cd (chr17: HOXB7), Mg (chr11: B4GALNT4), and Zn (chr17: FSCN2; chr20, LOC284798). In sensitivity analyses limited to children with cord blood DNAm data, eight 
Table 4 Overlapping cord blood differentially methylated regions for metals among infants overall (Sidak $p<0.05)$

\begin{tabular}{|c|c|c|c|c|c|c|}
\hline Analysis & Chr & Start & End & Gene & Length & $\begin{array}{l}\text { Number } \\
\text { of probes }\end{array}$ \\
\hline $\mathrm{Hg}$ & 6 & $30,039,374$ & $30,039,548$ & RNF39 & 175 & 12 \\
\hline $\mathrm{Mg}$ & & $30,039,175$ & $30,039,548$ & RNF39 & 374 & 13 \\
\hline $\mathrm{Mg}$ & 6 & $32,063,991$ & $32,064,258$ & $T N X B$ & 268 & 12 \\
\hline $\mathrm{Mn}$ & & $32,063,726$ & $32,064,161$ & TNXB & 436 & 13 \\
\hline Cs & 20 & $57,427,274$ & $57,427,762$ & GNAS;GNASAS & 489 & 16 \\
\hline $\mathrm{Cu}$ & & $57,427,426$ & $57,427,942$ & GNAS;GNASAS & 517 & 17 \\
\hline $\mathrm{Mg}$ & & $57,427,170$ & $57,427,973$ & GNAS;GNASAS & 804 & 24 \\
\hline
\end{tabular}

Differentially methylated regions (DMRs) identified using comb-p adjusted for infant sex, race/ethnicity, gestational age, nulliparous, maternal age at enrollment, prepregnancy BMI, education, smoking, household income, and estimated cord blood cell-type proportions

DMRs contained $100 \%$ of probes that were nominally significant in mid-childhood $(p<0.05)$, associated with Cd (chr2: 200,468,626-200,468,832; chr3: 156,323,952156,324,118; chr13: 110,319,562-110,319,607; chr17: HOXB7), Cs (chr4: 174,421,377-174,422,626; chr12; RAD52), Hg (chr8: LYNX1), and Zn (chr12: CACNA2D4) (Additional file 2: Spreadsheets 1-12).

\section{Conclusions}

We investigated epigenome-wide associations of prenatal concentrations of 12 metals measured in maternal firsttrimester RBC samples with cord blood DNAm and persistence DNAm changes in mid-childhood in the Project Viva pre-birth cohort. Overall we identified two CpGs at which cord blood DNAm was associated with specific metal levels in the first trimester: cg02042823 (A2BP1), associated with Mn, and cg20608990 (CASP8), associated with $\mathrm{Pb}$, and both DNAm associations seemed to persist in mid-childhood blood. Sex-specific associations with cord blood DNAm at individual CpGs were observed with Mn exposure ( 9 among females, and 2 CpGs among males that included cg02042823; FDR $<0.05$ ); the two male-specific cord blood DMPs were persistent while six of the female-specific DMPs were persistent in midchildhood blood DNAm. Multiple DMRs were identified with all prenatal metal exposures among infants overall with the exception of $\mathrm{Ba}$ and $\mathrm{Pb}$ (Sidak $p<0.05)$. We identified overlapping DNA methylation regions associated with prenatal exposure to $\mathrm{Cr}, \mathrm{Cs}, \mathrm{Cu}, \mathrm{Hg}, \mathrm{Mg}$, and $\mathrm{Mn}$ in the HLA region. The same cord blood DMR within the GNAS gene was associated with prenatal $\mathrm{Cs}, \mathrm{Cu}$, and $\mathrm{Mg}$ among all infants.

Although our study did not identify individual DMPs associated with exposure to metals other than Mn and $\mathrm{Pb}$, previous EWAS of selected prenatal exposures have identified DMPs. For example, among one of most widely studied metals, As, prior reports in other prenatal cohorts have documented multiple associated DMPs
[26, 28-30, 34-36]. These studies used maternal drinking water, urine, or nails to measure As exposure, which capture toxic inorganic forms of As. Urinary As in these studies was measured as the sum of inorganic species, whereas As is primarily present in inorganic forms in nail samples [37]. In our study, we used maternal RBCs which provide total arsenicals, including less toxic organic forms. In addition, the majority of previous studies have been conducted in populations with moderate-to-high As exposure, whereas exposure was low in our study. These factors potentially explain the lack of significant associations for our study. An EWAS of prenatal maternal blood Cd concentrations and DNAm in cord blood in a Bangladeshi cohort $(N=127)$ identified sex-specific effects more pronounced in boys, although no DMPs were statistically significant after adjustment for multiple comparisons [38]. This is in line with our study in which there was no evidence of DMPs associated with prenatal blood Cd levels. In our study median cadmium levels were much lower $(0.39 \mathrm{ng} / \mathrm{g})$ compared to median levels in the Bangladeshi study $(1.3 \mathrm{ug} / \mathrm{kg})$.

$\mathrm{Mn}$ is an essential trace element necessary for numerous biological functions including the metabolism of amino acids, proteins, lipids, and carbohydrates; immune function; energy regulation; and protection against free radicals [39]. Mn is also necessary for brain development and cognitive function, although $\mathrm{Mn}$ is a neurotoxicant at excessive levels [40], and in epidemiological studies, high levels of exposure to Mn prenatally have been negatively associated with measures of neurodevelopment $[8,41]$. Sex-specific associations have also been observed between prenatal Mn exposure and adolescent neuromotor [42] and neurobehavioral function [43], with high exposure associated with overall poorer outcomes among females compared with males. Few EWAS have previously investigated associations between prenatal Mn exposure and DNAm in offspring. An EWAS of placental DNAm and infant toenail Mn concentrations in 
Table 5 Summary of Gene Ontology (GO) enrichment analyses of cord blood differentially methylated regions (DMRs)

\begin{tabular}{|c|c|}
\hline \multirow[t]{7}{*}{$\mathrm{Cr}$} & Biosynthetic and metabolic processes of glycoproteins, organonitrogen compounds, and carbohydrate derivatives (BP) \\
\hline & Positive regulation of protein metabolic process (BP) \\
\hline & Negative regulation of signaling and response to stimulus (BP) \\
\hline & Regulation of cell death and apoptosis (BP) \\
\hline & Regulation of cell population proliferation (BP) \\
\hline & Circulatory system development (BP) \\
\hline & Protein domain-specific binding (MF) \\
\hline \multirow[t]{6}{*}{ Cs } & Cellular response to stress and oxidative stress (BP) \\
\hline & Cellular response to DNA damage (BP) \\
\hline & Organic substance metabolic processes including metabolism of peptides (BP) \\
\hline & Multicellular organism growth and skeletal system development (BP) \\
\hline & Protein-DNA complex assembly (BP) \\
\hline & Regulation of I-kappaB kinase/NF-kappaB signaling (BP) \\
\hline \multirow[t]{8}{*}{$\mathrm{Cu}$} & Cellular response to stress (BP) \\
\hline & Cellular response to DNA damage (BP) \\
\hline & Response to wounding (BP) \\
\hline & DNA metabolic process (BP) \\
\hline & Homeostasis and regulation of body fluid levels (BP) \\
\hline & Viral process (BP) \\
\hline & Biological process involved in symbiotic interaction (BP) \\
\hline & Nucleolus and nuclear protein-containing complex (CC) \\
\hline \multirow[t]{10}{*}{$\mathrm{Se}$} & Response to stress (BP) \\
\hline & Secretion and vesicle-mediated transport (BP) \\
\hline & Cell activation (BP) \\
\hline & Cytokine production and regulation of cytokine production (BP) \\
\hline & Programmed cell death (BP) \\
\hline & Immune and inflammatory response (BP) \\
\hline & Biological process involved in interspecies interaction between organisms (BP) \\
\hline & Secretion and vesicle-mediated transport (BP) \\
\hline & Extracellular space (CC) \\
\hline & Secretory vesicle and vesicle lumen (CC) \\
\hline \multirow[t]{5}{*}{$\mathrm{Zn}$} & Cation transport (BP) \\
\hline & Regulation of transmembrane transport (BP) \\
\hline & Sensory and visual system development (BP) \\
\hline & System and nervous system process (BP) \\
\hline & Multicellular organismal signaling (BP) \\
\hline
\end{tabular}

Prenatal exposure to $\mathrm{Cr}, \mathrm{Cs}, \mathrm{Cu}, \mathrm{Se}$, and $\mathrm{Zn}$ was associated with $18,20,17,41$, and $18 \mathrm{GO}$ terms, respectively $(p<0.05)$. GO terms were identified for multiple metals are: cellular response to DNA damage stimulus (GO:00069741, associated with $\mathrm{Cs}$ and $\mathrm{Cu}$ ), response to stress (GO:0006950, $\mathrm{Cu}$ and $\mathrm{Se}$ ), and cellular response to stress (GO:0033554; Cs and Cu). Closely related GO terms have been combined; for a complete list of DMR-associated GO terms, see Additional file 2: Spreadsheet 13

$B P$ biological process, $C C$ cellular component, $M F$ molecular function

a US birth cohort $(N=61)$ identified differential methylation at five CpGs with tertiles of Mn exposure $\left(p_{\text {Bon- }}\right.$ ferroni $<0.05)$ [44]; however, no Bonferroni-significant DMPs nor DMPs at $p<1 \times 10^{-4}$ overlapped with the Mnassociated DMPs or DMRs identified in our study. Given the sensitive window of prenatal development, timing of exposure and tissue used for Mn measurement could influence findings which might explain the lack of overlap in study results.
We identified Mn-associated DMPs annotated to genes with roles in neurodevelopment. Among infants overall and in stratified analyses of male infants, we found $\mathrm{Mn}$ exposure to be associated with greater methylation of cg02042823, annotated to Ataxin-2-binding protein 1 (A2BP1), also known as RNA binding fox-1 homolog 1 ( $R B F O X 1)$. A2BP1 is an RNA binding protein involved in tissue-specific pre-mRNA splicing of transcripts involved in neuronal development $[45,46]$. A2BP1-knockout mice 
have splicing changes in proteins involved in synaptic transmission and increased neuronal excitability [47]. In humans, $A 2 B P 1$ variants have been associated with biomarkers of Alzheimer's disease [48] and copy number variation of $A 2 B P 1$ has been associated with autism spectrum disorder [49]. We also found prenatal Mn exposure among females to be associated with methylation of cg19908812, annotated to Neuropeptide Y receptor Y1 (NPY1R), which encodes a transmembrane protein involved in neurotransmitter activity. NPY1R expression has been associated with anxious temperament in monkeys [50] and deletion involving NPY1R has been identified in a case study of autism [51]. Similarly, cg26462130, annotated to Mitotic arrest deficient 1 like 1 (MAD1L1), was associated with $\mathrm{Mn}$ in female infants. MAD1L1 is involved in mitotic spindle-assembly and genetic variation of MAD1L1 has been associated with schizophrenia [52] and anxiety disorders [53]. Whether our findings are implicated in neurodevelopmental disruption remains to be determined.

Prenatal $\mathrm{Pb}$ exposure has been negatively associated with mental and cognitive development and sensory function in infants and children [54-56]. In a previous study conducted in the Project Viva cohort, where $\mathrm{Pb}$ levels were below the CDC reference of $5 \mu \mathrm{g} / \mathrm{dL}$, there was a trend in lower neurobehavioral measures with higher prenatal $\mathrm{Pb}$ exposure [57]. Animal models have provided evidence that $\mathrm{Pb}$ effects global DNAm levels via DNA methyltransferase inhibition $[58,59]$, and prenatal $\mathrm{Pb}$ exposure has been negatively associated with global levels DNAm measured in cord blood [60]. There is limited research on epigenome-wide associations between $\mathrm{Pb}$ and locus-specific association with DNAm; however, an EWAS conducted in a Mexican pre-birth cohort $(N=420)$ identified no associations between prenatal exposure to $\mathrm{Pb}$ and cord blood DNAm [31]. Overall, we similarly found null results in $\mathrm{Pb}$ analyses with the exception of the DMP cg20608990, annotated to Caspase 8 (CASP8). CASP8 is involved in cell apoptosis [61], including neuronal apoptosis $[62,63]$, and cell death may be induced by $\mathrm{Pb}$ through a pathway involving CASP8 [64]. DNAm of the CASP8 promoter was not found to be associated with $\mathrm{Pb}$ and $\mathrm{Cd}$ exposure among children environmentally exposed through e-waste recycling $(N=116)$, although this study differed from our analyses in age participants (i.e., exposure and DNAm measured at 3-7 years old) [65]. In addition, this study measured DNAm at four loci within the CASP8 promoter using pyrosequencing.

In Project Viva, previous EWAS have been conducted for second-trimester maternal $\mathrm{RBC} \mathrm{Pb}(N=268)$ [32] and second-trimester maternal $\mathrm{RBC} \mathrm{Hg}$ [33] $(N=321)$. Using a look-up approach of CpGs associated with second-trimester $\mathrm{Pb}$, in our study first-trimester $\mathrm{Pb}$ was nominally associated with one $\mathrm{CpG}$ among all infants and four CpGs among females $(p<0.05)$, with a consistent direction of association across EWAS. In the EWAS of second-trimester $\mathrm{Hg}$, DNAm of cg13340705 (WBP11P1) and cg13416866 (TOR4A) was positively associated with exposure among infants overall and males, respectively $\left(p_{\text {Bonferroni }}<0.05\right)$ [33]. In the current analyses of first-trimester $\mathrm{RBC} \mathrm{Hg}$ concentrations, cg13416866 had a nominally significant positive association with $\mathrm{Hg}$ among males. In addition, Cardenas et al. identified one DMR associated with second-trimester $\mathrm{Hg}$ among male infants: chr7:94,953,653-94,954,202, annotated to Paraoxonase 1 (PON1) and consisting of 9 CpGs with negative associations with $\mathrm{Hg}(\mathrm{FDR}<0.05)$. Similarly, all CpGs in this region had a negative direction of association among males in our study of first-trimester $\mathrm{Hg}$, although only one was nominally associated with $\mathrm{Hg}$ (cg04871131, $p=0.026$ ). Limited replication of results between EWAS of first- and second-trimester exposures may be due to windows of susceptibility to epigenetic dysregulation or incomplete overlap between mother-infant pairs included in first-trimester and second-trimester EWAS of $\mathrm{Hg}$ and $\mathrm{Pb}$ in Project Viva. These results highlight the complexity of epigenetic dysregulation for trimesterspecific exposures during fetal development, a period of rapid epigenetic reprogramming.

Our study found multiple DMRs located in the HLA region associated with $\mathrm{Cr}, \mathrm{Cs}, \mathrm{Hg}, \mathrm{Mg}$, and $\mathrm{Mn}$, including common DMRs associated with $\mathrm{Hg}$ and $\mathrm{Mg}$ (annotated to RNF39) and $\mathrm{Mg}$ and $\mathrm{Mn}$ (annotated to TNXB). The HLA region spans a $\sim 4 \mathrm{Mb}$ segment of the chromosomal band 6p21 and contains an overrepresentation of protein-coding genes [66]. The HLA region is involved in immune regulation, including inflammation and innate and adaptive immunity, as well as reproduction, central nervous system development, and neurological disorders [66]. Ring Finger Protein 29 (RNF39) is a non-HLA expressed gene involved in regulation of synaptic plasticity [67]. RNF39 was found to be differentially expressed in rodent brains exposed to methylmercury [68], and differential methylation of RNF39 has been associated with schizophrenia spectrum disorders [69] and posttraumatic stress disorder [70]. Tenascin XB (TNXB) is also a non-HLA expressed gene, and TNXB methylation has similarly been associated with psychiatric disorders including social anxiety disorder [71] and anorexia nervosa [72]. We also identified multiple DMRs annotated to GNAS associated with $\mathrm{Cs}, \mathrm{Cu}$, and $\mathrm{Mg}$ among all infants, and with $\mathrm{Cu}$ and $\mathrm{Mg}$ among females. GNAS complex locus $(G N A S)$ is a protein-coding imprinted gene which includes four alternative exons. Methylation of GNAS has been associated with schizophrenia spectrum disorders 
[69], and parent-or-origin effects of SNPs have been associated with DNAm of GNAS [73]. In GO enrichment analysis of cord blood DMRs, $\mathrm{Cs}$ and $\mathrm{Cu}$ were nominally associated with GO terms including GNAS and involved in a broad range of biological processes including growth, development, response to stress, and metabolic processes.

In addition, GO analyses of DMRs identified similar terms nominally associated with multiple prenatal metals. Specifically, terms related to response to stress were enriched for Cs-, $\mathrm{Cu}-$, and Se-associated differentially methylated genes; terms related to apoptosis and cell death were enriched for $\mathrm{Cr}$ - and $\mathrm{Se}$-associated differentially methylated genes; and terms related to macromolecule metabolic processes were enriched for Cr-, Cs-, and $\mathrm{Cu}$-associated differentially methylated genes. Interestingly, differentially methylated genes in related pathways differed between metals, suggesting that prenatal metal exposures may affect common biological pathways through epigenetic regulation of multiple genes.

This study was strengthened by the use of maternal blood metal concentrations measured in the first trimester, which served as an unbiased biomarker of prenatal exposure in early life. We were also able to confirm reliability of maternal blood metal concentrations by calculating ICCs using duplicate samples. Overall, metal concentration measurements had good reliability (ICCs >0.70); however, $\mathrm{Cr}$ and $\mathrm{Cu}$ had lower ICCs $(0.40$ and 0.64 , respectively), which should be considered in interpreting the results from these EWAS. In addition, our study measured multiple metals in maternal blood samples and DNAm of offspring at birth and in midchildhood. This allowed us to compare EWAS results across prenatal metal exposures in the same population, as well as test for the persistence of differential methylation in childhood. Although our sample size was moderate, we were able to conduct stratified analyses to investigate sex-specific effects of metal exposures. It should be noted, however, that we adjusted for multiple comparisons within each metal EWAS (i.e., 394,460 probes), and we did not adjust for the number of metals tested or multiple testing introduced in sex-stratified analyses, which may increase the number of false-positives. This study was also strengthened by analyzing both locus-specific and regional differential methylation. DMRs were identified using the comb-p algorithm, which has been shown to have higher power and greater ability to identify DMRs with small effect sizes than other methods to detect DMRs [74] but at the expense of a higher Type I error rate [75]. Therefore, our results reflect candidate genomic positions associated with prenatal metal exposure, and the robustness of our findings should be tested in other cohorts and confirmed in meta-analyses.
Many of the DMRs we identified were restricted to sexstratified analyses, suggesting sexual dimorphism in the epigenomic effects of prenatal metal exposures; however, further research is needed to understand sex-specific regional differences in DNAm as most studies limit analyses across sex.

Several limitations of our study should be considered. Maternal blood metal exposure was assessed at a single time, and a single measurement may not capture critical windows of vulnerability during fetal development to epigenetic dysregulation. We also lacked data and samples for gene expression and cannot determine if changes in DNAm were associated with alterations in gene expression. In addition, although we investigated persistence of metal-induced epigenetic changes in mid-childhood, we did not have measures of childhood metal exposure which may also impact epigenetic programming. Most Mn-associated DMPs were nominally significant in midchildhood ( $p<0.05$ for all Mn-associated DMPs among infants overall and males, and $78 \%$ of DMPs among females); however, we observed limited persistence of DMRs in mid-childhood (four DMRs had $p<0.05$ in $100 \%$ of probes in mid-childhood). We are unable to assess how metal exposure between birth and mid-childhood may have affected DNA methylation levels. Our analyses of persistence of effects in mid-childhood were also limited by the incomplete overlap between motherinfant pairs with cord blood and mid-childhood DNAm data $(N=189$ mother-infant pairs with data at both time points). Furthermore, we chose to analyze associations between each metal exposure and DNAm separately to identify independent effects on epigenetic dysregulation. However, prenatal metal exposure may also act as a mixture to affect DMAm profiles. DNA methylation disruption across the genome resulting from prenatal maternal exposures appear non-targeted with multiple studies finding evidence of numerous associations that appear cohort specific. This might indicate the importance of taking into account environmental mixtures in epigenetic research. Statistical methods are needed in order to capture the complexity of environmental mixtures on the epigenome.

Few studies have investigated effects of multiple prenatal metal exposures on epigenome-wide DNAm and its persistence in childhood. In this study of 12 metals, we provide evidence that prenatal metal exposure is associated with cord blood DNAm at individual CpGs for two specific metals $(\mathrm{Mn}$ and $\mathrm{Pb})$. In addition, we observed associations between metal exposures and overlapping DMRs annotated to genes related to neurodevelopment and co-located in the HLA region, although analyses should be replicated in other cohorts to determine the generalizability of our findings. Further research may 
also provide insights to the effect of mixtures of prenatal metal exposures on epigenetic dysregulation as well as the impact of changes in DNAm on gene expression and biological pathways and child health outcomes.

\section{Methods}

\section{Study design}

Project Viva is a longitudinal pre-birth cohort established to examine associations between maternal diet and other environmental factors and maternal and child health. The Project Viva cohort has previously been described in detail [76]. Briefly, we recruited women between 1999 and 2002 from Atrius Harvard Vanguard Medical Associates, a group practice in eastern Massachusetts, US Research staff screened women at their initial obstetric visit (median 9.9 weeks of gestation). Exclusion criteria were multiple gestation, not English-speaking, $\geq 22$ weeks gestation, and plan to leave the study area prior to delivery. Initially, we included a total of 2,670 pregnancies (64\% of those screened), of which 2,128 live births remained in the cohort at the time of delivery (Additional file 1: Figure S1). For mothers with two children included in the current dataset $(N=2)$, we excluded the second birth from the current analyses.

At study recruitment (median $=10$ weeks gestation), research assistants administered a brief interview and provided mothers with a questionnaire to return by mail. Research assistants also conducted a mid-pregnancy visit, a hospital visit during the birth admission, and visits during infancy and mid-childhood (median 7.66 years). At birth, research assistants collected cord blood samples. Mothers provided written informed consent at enrollment and at the mid-childhood visit. Protocols for biosample collection were designed to minimize discomfort and inconvenience for mothers and children. The Institutional Review Board of Harvard Pilgrim Health Care reviewed and approved all study protocols.

\section{Sample collection, processing, and analysis}

Maternal RBC metal analysis: We collected blood samples from pregnant women at recruitment. We centrifuged blood samples $\left(2,000 \mathrm{rpm}\right.$ for $10 \mathrm{~min}$ at $\left.4{ }^{\circ} \mathrm{C}\right)$ to separate erythrocytes from plasma and stored aliquots at $-70{ }^{\circ} \mathrm{C}$ prior to analyses. We performed sample handling in an ISO class 6 clean room with an ISO class 5 laminar flow clean hood. Briefly, $0.5 \mathrm{ml}$ of packed erythrocytes was weighed and digested in $2 \mathrm{ml}$ of ultra-pure concentrated $\mathrm{HNO}_{3}$ acid for $48 \mathrm{~h}$, and then further digested with $1 \mathrm{ml}$ of $30 \%$ ultra-pure hydrogen peroxide for $24 \mathrm{~h}$ before diluting to $10 \mathrm{ml}$ with deionized water.

We measured first-trimester concentrations of the metals aluminum (Al), $\mathrm{As}, \mathrm{Ba}, \mathrm{Cd}$, cobalt $(\mathrm{Co})$; $\mathrm{Cr}, \mathrm{Cs}, \mathrm{Cu}$, $\mathrm{Mg}, \mathrm{Mn}$, molybdenum (Mo); nickel (Ni), $\mathrm{Pb}$, antimony
$(\mathrm{Sb})$, Se, tin (Sn), Tl: thallium, vanadium $(\mathrm{V})$, and $\mathrm{Zn}$ in erythrocytes using a triple quadrupole inductively coupled plasma mass spectrometry (ICP-MS) (Agilent 8800 ICP-QQQ) on a single run in MS/MS mode using appropriate cell gases and internal standards. We analyzed $\mathrm{Hg}$ concentrations separately using a Direct Mercury Analyzer 80 (Milestone Inc.). For Hg, three samples had insufficient quantity for analysis.

We applied the following quality control (QC) measures: analysis of initial and continuous calibration verification, procedural blanks, and repeated analysis of $2 \%$ of samples. In addition, Seronorm-Blood L3 was analyzed daily as QC samples with one blinded sample at high and low levels run per batch. Recoveries of QC standards were between 90 and $110 \%$ with the exception of $\mathrm{Al}, \mathrm{Sn}$, and $\mathrm{Sb}$ where measured values were below the limit of detection (LOD) out of the acceptable range $80-120 \%$. Intraday $\mathrm{CVs}$ were calculated using three concentrations of in-house QC pools $(n=7)$. Intraday CVs were $<5 \%$ for all analytes with the exception of $\mathrm{Se}$ and $\mathrm{Sb}$, which were $<10 \%$. Interday CVs for all elements were $<15 \%$ except for concentrations near the LOD. We measured metals concentrations as $\mathrm{ng} / \mathrm{g}$ red blood cells. In this analysis, we include only metals that met the quality control criteria of percent detected $\geq 80 \%$ and intraclass correlation coefficients (ICCs) $\geq 0.70$ among duplicates, with the exception of $\mathrm{Cr}$ and $\mathrm{Cu}$ which had ICCs $=0.40$ and 0.64 , respectively, but had detectable measures in over $80 \%$ of the samples.

Infant and child blood and DNAm analysis: Clinicians collected cord blood at delivery using a syringe and needle from the umbilical vein. Paper or electronic "flags" on participants' charts were used to prompt clinical staff to collect samples, and cord blood samples were collected from approximately $75 \%$ of participants who delivered at the study hospitals. We collected fasting blood samples from children at the mid-childhood visit using ethylenediaminetetraacetic acid (EDTA)-containing vacutainer tubes, and put samples on ice. To separate plasma, nucleated cells (including leukocytes and nucleated RBCs in cord blood and leukocytes in child blood), and RBCs, we centrifuged the tubes at $1,700 \times \mathrm{g}$ for $10 \mathrm{~min}$ at $4{ }^{\circ} \mathrm{C}$ within $24 \mathrm{~h}$ of collection.

Measurement of DNAm has previously been described [32]. Briefly, we extracted genomic DNA from the nucleated cells with PureGene Kits (Fisher, Catalog Nos. A407-4, A416-4; Qiagen, Catalog Nos. 158908, 158912, 158924), and we stored sample aliquots at $-80{ }^{\circ} \mathrm{C}$ until analysis. Research staff performed bisulfite conversion using the Zymo DNA Methylation kit (Zymo Research, Irvine, CA). One $\mu \mathrm{g}$ DNA of each sample was randomized across plates and BeadChips to reduce batch effects. DNAm analysis was performed at Illumina, Inc. 
using the Illumina Infinium HumanMethylation450 (450K) BeadChip (Illumina, San Diego, CA). The 450K microarray interrogates $>485,000$ methylation loci at single-nucleotide resolution.

\section{Covariates}

We collected maternal demographics (including education and household income), smoking status, and prepregnancy height and weight through self-administered questionnaires and interviews during pregnancy. We estimated maternal fish intake as servings per week for the first trimester or period closest to blood draw using a semi-quantitative food frequency questionnaire [77]. We used maternal self-reported height and weight to calculate pre-pregnancy body mass index $\left(\mathrm{BMI} ; \mathrm{kg} / \mathrm{m}^{2}\right)$. We estimated gestational age from mothers' last menstrual period (LMP) at enrollment; we used gestational age determined by ultrasound if available and differed from LMP by $>10$ days [76].

\section{Data processing}

DNAm data were preprocessed using the $\mathrm{R}$ package minfi [78]. We excluded duplicate samples, samples with low individual call rates $(<0.98)$, and samples that had a genotype or sex mismatch $(N=22$ cord blood DNAm; Additional file 1: Figure S1). Non-CpG probes and probes with detection $p$ values $>0.05$ for $>1 \%$ of samples were dropped. In addition, we excluded probes located on sex the chromosomes, cross hybridizing probes [79], and probes associated with single-nucleotide polymorphisms (SNPs) that have a minor allele frequency $\geq 0.05$ at the single base extension or within the target region. A total of 394,460 high-quality probes remained for analyses. We performed background correction and dye-bias equalization using the normal-exponential out-of-band method (noob) [80], and probe-type normalization using the beta-mixture quantile method (BMIQ) implemented through minfi. We estimated cell-type composition using the Houseman regression calibration method [81] implemented in the minfi package [78] using reference panels derived from cord blood nucleated cells for cord blood cell-type estimates [82] and adult leukocytes for midchildhood cell-type estimates [83].

\section{Data analysis}

Metal concentrations $<$ the LOD were replaced with $\mathrm{LOD} / \sqrt{ } 2$. The LODs and the number of samples < LOD for each metal were: As: $0.153 \mathrm{ng} / \mathrm{g}(N=35)$; Ba: $0.412 \mathrm{ng} / \mathrm{g}(N=5)$; Cd: $0.0569 \mathrm{ng} / \mathrm{g}(N=19)$ : $\mathrm{Cr}$ : $0.685 \mathrm{ng} / \mathrm{g}(N=37) ; \mathrm{Cs}: 0.0587 \mathrm{ng} / \mathrm{g}(N=0) ; \mathrm{Cu}: 1.85 \mathrm{ng} / \mathrm{g}$ $(N=0) ; \mathrm{Hg}: 0.3 \mathrm{ng} / \mathrm{g}(N=9) ; \mathrm{Mg}: 4.15 \mathrm{ng} / \mathrm{g}(N=0) ; \mathrm{Mn}$ : $0.422 \mathrm{ng} / \mathrm{g}(N=0) ; \mathrm{Pb}: 0.0746 \mathrm{ng} / \mathrm{g}(N=0) ;$ Se: $1.73 \mathrm{ng} / \mathrm{g}$
$(N=0) ; \mathrm{Zn}: 8.74 \mathrm{ng} / \mathrm{g}(N=0)]$. Prior to analyses, we $\log _{2}$ transformed metal concentrations to meet model assumptions as metals were right skewed.

We presented descriptive statistics for participant characteristics and metal concentration using medians and interquartile ranges (IQRs) for continuous variables and frequencies and proportions for categorical variables. We assessed differences between mother-infant pairs with cord blood and mid-childhood DNAm data using the Mann-Whitney test for continuous variables and Chi-squared test for categorical variables. We tested associations between prenatal first-trimester metal concentrations and estimated cord blood cell-type proportions [B cells, CD4 $+\mathrm{T}$ cells, CD8 $+\mathrm{T}$ cells, granulocytes, monocytes, natural killer (NK) cells, and nucleated RBCs] with linear models adjusted for infant sex, race/ethnicity, gestational age, nulliparous, maternal age at enrollment, pre-pregnancy BMI, education (<college graduate or college graduate), household income $(\leq \$ 70,000$ per year or $>\$ 70,000$ per year), and maternal smoking (never, former, or smoking during pregnancy).

We conducted EWAS for DMPs (i.e., individual CpGs) using linear regression with empirical Bayes smoothing of standard errors with the robust estimator for prior variances implemented using the $\mathrm{R}$ package limma [84]. To better meet models assumptions, we performed analyses using the logit-transformation of Beta-values (i.e., $\mathrm{M}$-value $=\ln [$ Beta-value / $(1-$ Beta-value)]) [85]. We conducted EWAS using limma independently for each $\log _{2}$-transformed prenatal metal concentration (i.e., 12 EWAS of cord blood DNAm). Overall, we adjusted cord blood models for infant sex, race/ethnicity, gestational age, nulliparous, maternal age at enrollment, prepregnancy BMI, education, household income, maternal smoking, and estimated cell-type distribution (B cells, $\mathrm{CD} 4+\mathrm{T}$ cells, CD8 + T cells, granulocytes, monocytes, NK cells, and nucleated RBCs). For each analysis, we generated Q-Q plots and calculated the genomic inflation factor $(\lambda)$ to evaluate potential systematic biases. Within each metal EWAS, we used the Benjamini-Hochberg false discovery rate (FDR) method [86] to adjust for multiple comparisons using the p.adjust function in $\mathrm{R}$. To address potential effect modification by infant sex, we performed limma analyses for infants overall and stratified by sex. For FDR-significant probes in sex-stratified analyses, we further evaluated effect modification using linear models including a metal $\times$ sex interaction term. We performed sensitivity analysis for associations with As and $\mathrm{Hg}$ including the covariate of maternal fish consumption during pregnancy. We report DMP effect sizes on the Beta-value scale for interpretability.

We analyzed DMRs using the comb- $p$ method [87] implemented in the $\mathrm{R}$ package ENmix [88]. Comb-p 
identities DMRs using all EWAS $p$ values and associated chromosomal coordinates by first adjusting for autocorrelation between nearby probes using the Stouffer-LiptakKechris (slk) correction (e.g., $p$ values with adjacent low values will be pulled lower). An FDR correction is applied to $s l k$-adjusted $p$ values, regions are identified among probes meeting a specified FDR threshold, and a single $s l k$-adjusted $p$ value is calculated for each region. Correction for multiple comparisons is performed on regional $p$ values using a Sidak correction based on the total number of possible regions. We performed comb-p using the arguments of a maximum distance to combine DMRs of 1,000 base pairs, the recommended bin size for autocorrelation of 310, and the FDR significance threshold of 0.001 . Regions containing only one probe were excluded, and regions with Sidak $p<0.05$ were considered significant. GO enrichment analysis of DMRs was performed using goregion implemented in the $\mathrm{R}$ package missMethy $[89,90]$. The goregion function uses genes annotated to DMRs to identify GO terms including an overrepresentation of differentially methylated genes while accounting for coverage of genes on the 450K microarray [91]. goregion was implemented independently for each metal with the input of cord blood DMRs (Sidak $p<0.05$ ) and all CpGs included in analyses. REVIGO was used to aid in interpretation of relationships between identified GO terms [92].

To test the persistence of observed associations between prenatal metal exposure and cord blood DNAm, we performed limma analyses with mid-childhood DNAm. Models included the covariates of infant sex, race/ethnicity, child age at blood draw, nulliparous, maternal age at enrollment, pre-pregnancy BMI, education, household income, maternal smoking, and midchildhood estimated cell-type composition (B cells, $\mathrm{CD} 4+\mathrm{T}$ cells, CD8 $+\mathrm{T}$ cells, granulocytes, monocytes, and NK cells). We performed sensitivity analyses restricting samples to children included in the cord blood DNAm analyses. We used a nominal $p$ value $<0.05$ along with consistency of direction of association to evaluate persistence of associations in mid-childhood.

To compare our findings of results of previous EWAS of second-trimester maternal $\mathrm{RBC} \mathrm{Hg}$ and $\mathrm{Pb}$ in Project Viva [32, 33], we used a look-up approach of CpGs identified as associated with $\mathrm{Hg}$ and $\mathrm{Pb}$ by Wu et al. and Cardenas et al., respectively. We used an unadjusted $p$ value $<0.05$ and direction of association to determine consistency of results between EWAS of first- and second-trimester metal exposures.

We performed all data analysis using R 4.0.3. [93].

\section{Abbreviations}

Cu: Copper; Mg: Magnesium; Mn: Manganese; Se: Selenium; Zn: Zinc; As: Arsenic; Cd: Cadmium; Pb: Lead; Hg: Mercury; DOHaD: Developmental origins of health and disease; DNAm: DNA methylation; EWAS: Epigenome-wide association study; DMPs: Differentially methylated positions; US: United States; RBCs: Red blood cells; Ba: Barium; Cr: Chromium; Cs: Cesium; DMRs: Differentially methylated regions; LOD: Limit of detection; IQR: Interquartile range; DMPs: Differentially methylated positions; DMRs: Differentially methylated regions; Al: Aluminum; Co: Cobalt; Mo: Molybdenum; Ni: Nickel; Sb: Antimony; Sn: Tin; TI: Thallium; V: Vanadium; ICP-MS: Inductively coupled plasma mass spectrometry; QC: Quality control; LOD: Limit of detection; ICC: Intraclass correlation coefficients; EDTA: Ethylenediaminetetraacetic acid; 450K microarray: Illumina Infinium HumanMethylation450 BeadChip; FFQ: Food frequency questionnaire; BMI: Body mass index; LMP: Last menstrual period; SNPs: Single-nucleotide polymorphism; noob: Normal-exponential out-of-band; BMIQ: Beta-mixture quantile; IQRs: Interquartile ranges; NK: Natural killer cells; FDR: False discovery rate; slk: Stouffer-Liptak-Kechris; A2BP1: Ataxin-2-binding protein 1; GO: Gene ontology; RBFOX1: RNA binding fox-1 homolog 1; NPY1R: Neuropeptide Y receptor Y1; MAD1L1: Mitotic arrest deficient 1 like 1; CASP8: Caspase 8; RNF39: RING finger protein 39; TNXB: Tenascin XB; GNAS: GNAS complex locus; PON1: Paraoxonase 1.

\section{Supplementary Information}

The online version contains supplementary material available at https://doi. org/10.1186/s13148-021-01198-z.

\section{Additional file 1}

Additional file 2

\section{Acknowledgements}

The measurement of metals was funded by the Children's Health Exposure Analysis Resource (CHEAR) (CHEAR award \#2017-1740-U2CES026561) and was conducted at the Mount Sinai CHEAR Network Laboratory.

\section{Authors' contributions}

AKB developed the data analysis plan, analyzed and visualized data, and drafted the manuscript; SLR-S was involved in developing study methodology and data management and reviewed and edited the manuscript; BAC was involved in developing study methodology and reviewed and edited the manuscript; $A A B$ reviewed and edited the manuscript; ROW was involved in funding acquisition and reviewed and edited the manuscript; CA was involved in sample processing and reviewed and edited the manuscript; DRG was involved in developing study methodology and reviewed and edited the manuscript; EO was involved in developing study methodology and funding acquisition and reviewed and edited the manuscript; $\mathrm{M}-\mathrm{FH}$ was involved in developing study methodology and reviewed and edited the manuscript; Andres Cardenas conceptualized the project, developed the data analysis plan, was involved in developing study methodology and funding acquisition, and reviewed and edited the manuscript. All authors read and approved the final manuscript.

\section{Funding}

This work was supported by the United States National Institutes of Health Grants R01ES031259, R01HD034568, and UH3OD023286.

\section{Availability of data and materials}

Datasets generated and analyzed during the current study are not publicly available because we did not obtain consent for such public release of epigenetic data from participants. However, raw data to generate figures and tables are available from the corresponding author with the appropriate permission from the Project Viva study team and investigators (project viva@hphc.org) upon reasonable request and institutional review board approval. R code for all analyses is available at the study's GitHub repository (https://github.com/ annebozack/viva_DNAm_metals). Complete cord blood EWAS results for all metals are available at GitHub repository and Open Science Framework (OSF) site (https://osf.io/jf5yt/). 


\section{Declarations}

\section{Ethics approval and consent to participate}

Mothers provided written informed consent at enrollment and at the midchildhood visit. Protocols for biosample collection were designed to minimize discomfort and inconvenience for mothers and children. The Institutional Review Board of Harvard Pilgrim Health Care reviewed and approved all study protocols.

\section{Consent for publication}

Not applicable.

\section{Competing interests}

The authors declare they have no competing interests.

\section{Author details}

${ }^{1}$ Division of Environmental Health Sciences, School of Public Health, University of California Berkeley, 2121 Berkeley Way, Room 5302, Berkeley, CA 94720, USA. ${ }^{2}$ Division of Chronic Disease Research Across the Lifecourse, Department of Population Medicine, Harvard Medical School and Harvard Pilgrim Health Care Institute, Boston, MA, USA. ${ }^{3}$ Department of Biostatistics, Harvard T.H. Chan School of Public Health, Harvard University, Boston, MA, USA. ${ }^{4}$ Department of Environmental Health Sciences, Mailman School of Public Health, Columbia University, New York City, NY, USA. ${ }^{5}$ Department of Environmental Medicine and Public Health and Institute for Exposomic Research, Icahn School of Medicine at Mount Sinai, NY, New York City, USA. ${ }^{6}$ Channing Division of Network Medicine, Department of Medicine, Brigham and Women's Hospital, Boston, MA, USA. ${ }^{7}$ Department of Environmental Health, Harvard T.H. Chan School of Public Health, Harvard University, Boston, MA, USA. ${ }^{8}$ Harvard Medical School, Boston, MA, USA. 'Diabetes Unit, Massachusetts General Hospital, Boston, MA, USA. ${ }^{10} \mathrm{Center}$ for Computational Biology, University of California, Berkeley, CA, USA.

Received: 17 September 2021 Accepted: 8 November 2021 Published online: 19 November 2021

\section{References}

1. McArdle HJ, Ashworth CJ. Micronutrients in fetal growth and development. Br Med Bull Engl. 1999;55:499-510.

2. Gambling L, Kennedy C, McArdle HJ. Iron and copper in fetal development. Semin Cell Dev Biol Engl. 2011;22:637-44.

3. Fanni D, Gerosa C, Nurchi VM, Manchia M, Saba L, Coghe F, et al. The role of magnesium in pregnancy and in fetal programming of adult diseases. Biol Trace Element Res. 2020. https://doi.org/10.1007/ s12011-020-02513-0.

4. Wood RJ. Manganese and birth outcome. Nutr Rev. 2009;67:416-20.

5. Rayman MP. The importance of selenium to human health. Lancet England. 2000;356:233-41.

6. Saper RB, Rash R. Zinc: an essential micronutrient. Am Fam Physician. 2009:79:768-72

7. Li Z, Liang C, Huang K, Yan S, Tao R, Sheng J, et al. Umbilical serum copper status and neonatal birth outcomes: a prospective cohort study. Biol Trace Elem Res US. 2018;183:200-8.

8. Chung SE, Cheong H-K, Ha E-H, Kim B-N, Ha M, Kim Y, et al. Maternal blood manganese and early neurodevelopment: the Mothers and Children's Environmental Health (MOCEH) Study. Environ Health Perspect. 2015:123:717-22.

9. Skröder HM, Hamadani JD, Tofail F, Persson LÅ, Vahter ME, Kippler MJ. Selenium status in pregnancy influences children's cognitive function at 1.5 years of age. Clin Nutr Eng. 2015;34:923-30.

10. Varsi K, Bolann B, Torsvik I, Rosvold Eik TC, Høl PJ, Bjørke-Monsen A-L. Impact of maternal selenium status on infant outcome during the first 6 months of life. Nutrients. 2017;9:486.

11. Jaishankar M, Tseten T, Anbalagan N, Mathew BB, Beeregowda KN. Toxicity, mechanism and health effects of some heavy metals. Interdiscip Toxicol. 2014;7:60-72.

12. Shen S, Li X-F, Cullen WR, Weinfeld M, Le XC. Arsenic binding to proteins. Chem Rev. 2013;113:7769-92.
13. Milton AH, Hussain S, Akter S, Rahman M, Mouly TA, Mitchell K. A review of the effects of chronic arsenic exposure on adverse pregnancy outcomes. Int J Environ Res Public Health. 2017;14:556

14. Shirai S, Suzuki Y, Yoshinaga J, Mizumoto Y. Maternal exposure to low-level heavy metals during pregnancy and birth size. J Environ Sci Health A Tox Hazard Subst Environ Eng Engl. 2010;45:1468-74.

15. Zhu M, Fitzgerald EF, Gelberg KH, Lin S, Druschel CM. Maternal low-level lead exposure and fetal growth. Environ Health Perspect. 2010;118:1471-5.

16. Bellinger DC. Very low lead exposures and children's neurodevelopment. Curr Opin Pediatr United States. 2008;20:172-7.

17. Bose-O'Reilly S, McCarty KM, Steckling N, Lettmeier B. Mercury exposure and children's health. Curr Probl Pediatr Adolesc Health Care. 2010:40:186-215.

18. Tolins M, Ruchirawat M, Landrigan P. The developmental neurotoxicity of arsenic: cognitive and behavioral consequences of early life exposure. Ann Glob Health. 2014;80:303-14.

19. Wang Y, Chen L, Gao Y, Zhang Y, Wang C, Zhou Y, et al. Effects of prenatal exposure to cadmium on neurodevelopment of infants in Shandong. China Environ Pollut England. 2016:211:67-73.

20. Signes-Pastor AJ, Doherty BT, Romano ME, Gleason KM, Gui J, Baker $E$, et al. Prenatal exposure to metal mixture and sex-specific birth outcomes in the New Hampshire Birth Cohort Study. Environ Epidemiol. 2019:3:e068.

21. Vahter M, Akesson A, Lidén C, Ceccatelli S, Berglund M. Gender differences in the disposition and toxicity of metals. Environ Res Netherlands. 2007:104:85-95.

22. Rahman ML, Oken E, Hivert M-F, Rifas-Shiman S, Lin P-ID, Colicino E, et al. Early pregnancy exposure to metal mixture and birth outcomes-a prospective study in Project Viva. Environ Int. Netherlands; 2021;156:106714.

23. Heindel JJ, Vandenberg LN. Developmental origins of health and disease: a paradigm for understanding disease cause and prevention. Curr Opin Pediatr NIH Public Access. 2015;27:248-53.

24. Wadhwa PD, Buss C, Entringer S, Swanson JM. Developmental origins of health and disease: brief history of the approach and current focus on epigenetic mechanisms. Semin Reprod Med. 2009;27:358-68.

25. Martin EM, Fry RC. Environmental influences on the epigenome: exposure-associated DNA methylation in human populations. Annu Rev Public Health. 2018;39:309-33.

26. Green BB, Karagas MR, Punshon T, Jackson BP, Robbins DJ, Houseman EA, et al. Epigenome-wide assessment of DNA methylation in the placenta and arsenic exposure in the New Hampshire Birth Cohort Study. Environ Health Perspect. 2016;124:1253-60.

27. Koestler DC, Avissar-Whiting M, Houseman EA, Karagas MR, Marsit CJ. Differential DNA methylation in umbilical cord blood of infants exposed to low levels of arsenic in utero. Environ Health Perspect. 2013;121:971-7.

28. Broberg K, Ahmed S, Engström K, Hossain MB, Jurkovic Mlakar S, Bottai $M$, et al. Arsenic exposure in early pregnancy alters genome-wide DNA methylation in cord blood, particularly in boys. J Dev Orig Health Dis. 2014;5:288-98.

29. Cardenas A, Houseman EA, Baccarelli AA, Quamruzzaman Q, Rahman M, Mostofa G, et al. In utero arsenic exposure and epigenome-wide associations in placenta, umbilical artery, and human umbilical vein endothelial cells. Epigenetics. 2015;10:1054-63.

30. Rojas D, Rager JE, Smeester L, Bailey KA, Drobná Z, Rubio-Andrade M, et al. Prenatal arsenic exposure and the epigenome: identifying sites of 5-methylcytosine alterations that predict functional changes in gene expression in newborn cord blood and subsequent birth outcomes. Toxicol Sci. 2015;143:97-106.

31. Heiss JA, Téllez-Rojo MM, Estrada-Gutiérrez G, Schnaas L, Amarasiriwardena C, Baccarelli AA, et al. Prenatal lead exposure and cord blood DNA methylation in PROGRESS: an epigenome-wide association study. Environ Epigenet. 2020;6:dvaa014.

32. Wu S, Hivert M-F, Cardenas A, Zhong J, Rifas-Shiman SL, Agha G, et al. Exposure to low levels of lead in utero and umbilical cord Blood DNA methylation in Project Viva: an epigenome-wide association study. Environ Health Perspect. 2017;125:087019.

33. Cardenas A, Rifas-Shiman SL, Agha G, Hivert MF, Litonjua AA, DeMeo DL, et al. Persistent DNA methylation changes associated with prenatal mercury exposure and cognitive performance during childhood. Sci Rep. Nature Publishing Group. 2017;7:288. 
34. Bozack AK, Cardenas A, Quamruzzaman Q, Rahman M, Mostofa G, Christiani DC, et al. DNA methylation in cord blood as mediator of the association between prenatal arsenic exposure and gestational age. Epigenetics. 2018;13:923-40.

35. Kaushal A, Zhang H, Karmaus WJJ, Everson TM, Marsit CJ, Karagas MR, et al. Genome-wide DNA methylation at birth in relation to in utero arsenic exposure and the associated health in later life. Environ Health. 2017; 16:50.

36. Kile ML, Houseman EA, Baccarelli AA, Quamruzzaman Q, Rahman M, Mostofa $G$, et al. Effect of prenatal arsenic exposure on DNA methylation and leukocyte subpopulations in cord blood. Epigenetics. 2014;9:774-82.

37. Button M, Jenkin GRT, Harrington CF, Watts MJ. Human toenails as a biomarker of exposure to elevated environmental arsenic. J Environ Monit England. 2009;11:610-7.

38. Kippler M, Engström K, Mlakar SJ, Bottai M, Ahmed S, Hossain MB, et al. Sex-specific effects of early life cadmium exposure on DNA methylation and implications for birth weight. Epigenetics. 2013;8:494-503.

39. Aschner JL, Aschner M. Nutritional aspects of manganese homeostasis. Mol Aspects Med. 2005;26:353-62.

40. Balachandran RC, Mukhopadhyay S, McBride D, Veevers J, Harrison FE, Aschner M, et al. Brain manganese and the balance between essential roles and neurotoxicity. J Biol Chem. 2020;295:6312-29.

41. Lin C-C, Chen Y-C, Su F-C, Lin C-M, Liao H-F, Hwang Y-H, et al. In utero exposure to environmental lead and manganese and neurodevelopment at 2 years of age. Environ Res Netherl. 2013;123:52-7.

42. Chiu Y-HM, Henn BC, Hsu H-HL, Pendo MP, Coull BA, Austin C, et al. Sex differences in sensitivity to prenatal and early childhood manganese exposure on neuromotor function in adolescents. Environ Res. 2017:159:458-65.

43. Bauer JA, Henn BC, Austin C, Zoni S, Fedrighi C, Cagna G, et al. Manganese in teeth and neurobehavior: sex-specific windows of susceptibility. Environ Int. 2017;108:299-308.

44. Maccani JZJ, Koestler DC, Houseman EA, Armstrong DA, Marsit CJ, Kelsey KT. DNA methylation changes in the placenta are associated with fetal manganese exposure. Reprod Toxicol. 2015;57:43-9.

45. Fogel BL, Wexler E, Wahnich A, Friedrich T, Vijayendran C, Gao F, et al. RBFOX1 regulates both splicing and transcriptional networks in human neuronal development. Hum Mol Genet. 2012;21:4171-86.

46. Kuroyanagi H. Fox-1 family of RNA-binding proteins. Cell Mol Life Sci. 2009;66:3895-907.

47. Gehman LT, Stoilov P, Maguire J, Damianov A, Lin C-H, Shiue L, et al. The splicing regulator Rbfox1 (A2BP1) controls neuronal excitation in the mammalian brain. Nat Genet. 2011;43:706-11.

48. Kong L-L, Miao D, Tan L, Liu S-L, Li J-Q, Cao X-P, et al. Genome-wide association study identifies RBFOX1 locus influencing brain glucose metabolism. Ann Transl Med. 2018;6:436

49. Bill BR, Lowe JK, Dybuncio CT, Fogel BL. Orchestration of neurodevelopmental programs by RBFOX1: implications for autism spectrum disorder Int Rev Neurobiol. 2013;113:251-67.

50. Roseboom PH, Nanda SA, Fox AS, Oler JA, Shackman AJ, Shelton SE, et al. Neuropeptide $Y$ receptor gene expression in the primate amygdala predicts anxious temperament and brain metabolism. Biol Psychiatry. 2014;76:850-7.

51. Ramanathan S, Woodroffe A, Flodman PL, Mays LZ, Hanouni M, Modahl $C B$, et al. A case of autism with an interstitial deletion on $4 \mathrm{q}$ leading to hemizygosity for genes encoding for glutamine and glycine neurotransmitter receptor sub-units (AMPA 2, GLRA3, GLRB) and neuropeptide receptors NPY1R, NPY5R. BMC Med Genet. 2004;5:10.

52. Su L, Shen T, Huang G, Long J, Fan J, Ling W, et al. Genetic association of GWAS-supported MAD1L1 gene polymorphism rs12666575 with schizophrenia susceptibility in a Chinese population. Neurosci Lett Ireland. 2016:610:98-103.

53. Levey DF, Gelernter J, Polimanti R, Zhou H, Cheng Z, Aslan M, et al. Reproducible genetic risk loci for anxiety: results from $~ 200,000$ participants in the Million Veteran Program. Am J Psychiatry. 2020;177:223-32.

54. Schnaas L, Rothenberg SJ, Flores M-F, Martinez S, Hernandez C, Osorio E, et al. Reduced intellectual development in children with prenatal lead exposure. Environ Health Perspect. 2006;114:791-7.

55. Shah-Kulkarni S, Ha M, Kim B-M, Kim E, Hong Y-C, Park H, et al. Neurodevelopment in early childhood affected by prenatal lead exposure and iron intake. Medicine. 2016:95:e2508.
56. Silver MK, Li X, Liu Y, Li M, Mai X, Kaciroti N, et al. Low-level prenatal lead exposure and infant sensory function. Environ Health. 2016;15:65.

57. Fruh V, Rifas-Shiman SL, Amarasiriwardena C, Cardenas A, Bellinger DC, Wise LA, et al. Prenatal lead exposure and childhood executive function and behavioral difficulties in Project Viva. Neurotoxicology. 2019;75:105-15.

58. Sanchez OF, Lee J, King Hing NY, Kim S-E, Freeman JL, Yuan C. Lead (Pb) exposure reduces global DNA methylation level by non-competitive inhibition and alteration of dnmt expression. Metallomics Engl. 2017:9:149-60

59. Schneider JS, Kidd SK, Anderson DW. Influence of developmental lead exposure on expression of DNA methyltransferases and methyl cytosinebinding proteins in hippocampus. Toxicol Lett. 2013;217:75-81.

60. Pilsner JR, Hu H, Ettinger A, Sánchez BN, Wright RO, Cantonwine D, et al Influence of prenatal lead exposure on genomic methylation of cord blood DNA. Environ Health Perspect. 2009;117:1466-71.

61. Galluzzi L, López-Soto A, Kumar S, Kroemer G. Caspases connect cell-death signaling to organismal homeostasis. Immunity US. 2016;44:221-31.

62. Ivins KJ, Thornton PL, Rohn TT, Cotman CW. Neuronal apoptosis induced by beta-amyloid is mediated by caspase-8. Neurobiol Dis United States. 1999:6:440-9.

63. Monnier PP, D'Onofrio PM, Magharious M, Hollander AC, Tassew N, Szydlowska K, et al. Involvement of caspase- 6 and caspase-8 in neuronal apoptosis and the regenerative failure of injured retinal ganglion cells. J Neurosci. 2011;31:10494-505.

64. He X, Wu J, Yuan L, Lin F, Yi J, Li J, et al. Lead induces apoptosis in mouse TM3 Leydig cells through the Fas/FasL death receptor pathway. Environ Toxicol Pharmacol Netherl. 2017;56:99-105.

65. Xu L, Huo X, Liu Y, Zhang Y, Qin Q, Xu X. Hearing loss risk and DNA methylation signatures in preschool children following lead and cadmium exposure from an electronic waste recycling area. Chemosphere. 2020;246:125829.

66. Shiina T, Hosomichi K, Inoko H, Kulski JK. The HLA genomic loci map: expression, interaction, diversity and disease. J Hum Genet. 2009:54:15-39.

67. Matsuo R, Asada A, Fujitani K, Inokuchi K. LIRF, a gene induced during hippocampal long-term potentiation as an immediate-early gene, encodes a novel RING finger protein. Biochem Biophys Res Commun United States. 2001;289:479-84.

68. Radonjic M, Cappaert NLM, de Vries EFJ, de Esch CEF, Kuper FC, van Waarde A, et al. Delay and impairment in brain development and function in rat offspring after maternal exposure to methylmercury. Toxicol Sci. 2013;133:112-24.

69. Carmel M, Michaelovsky E, Weinberger R, Frisch A, Mekori-Domachevsky $\mathrm{E}$, Gothelf $\mathrm{D}$, et al. Differential methylation of imprinting genes and $\mathrm{MHC}$ locus in 22q11.2 deletion syndrome-related schizophrenia spectrum disorders. World J Biol Psychiatry. 2020;0:1-12.

70. Rutten BPF, Vermetten E, Vinkers $C H$, Ursini G, Daskalakis NP, Pishva E, et al. Longitudinal analyses of the DNA methylome in deployed military servicemen identify susceptibility loci for post-traumatic stress disorder. Mol Psychiatry. 2018;23:1145-56.

71. Wiegand A, Kreifelts B, Munk MHJ, Geiselhart N, Ramadori KE, Maclsaac JL, et al. DNA methylation differences associated with social anxiety disorder and early life adversity. Transl Psychiatry. 2021;11:104.

72. Kesselmeier M, Pütter C, Volckmar A-L, Baurecht H, Grallert H, Illig T, et al. High-throughput DNA methylation analysis in anorexia nervosa confirms TNXB hypermethylation. World J Biol Psychiatry Engl. 2018;19:187-99.

73. Cuellar Partida G, Laurin C, Ring SM, Gaunt TR, McRae AF, Visscher PM, et al. Genome-wide survey of parent-of-origin effects on DNA methylation identifies candidate imprinted loci in humans. Hum Mol Genet. 2018:27:2927-39.

74. Mallik S, Odom GJ, Gao Z, Gomez L, Chen X, Wang L. An evaluation of supervised methods for identifying differentially methylated regions in Illumina methylation arrays. Brief Bioinform. 2018;20:2224-35.

75. Lent S, Cardenas A, Rifas-Shiman SL, Perron P, Bouchard L, Liu C-T, et al. Detecting differentially methylated regions with multiple distinct associations. Epigenomics. 2021;13:451-64.

76. Oken E, Baccarelli AA, Gold DR, Kleinman KP, Litonjua AA, De Meo D, et al. Cohort profile: project viva. Int J Epidemiol. 2015;44:37-48. 
77. Rifas-Shiman SL, Rich-Edwards JW, Kleinman KP, Oken E, Gillman MW. Dietary quality during pregnancy varies by maternal characteristics in Project Viva: a US cohort. J Am Diet Assoc. 2009;109:1004-11.

78. Aryee M, Jaffe A, Corrada-Bravo H, Ladd-Acosta C, Feinberg A, Hansen K, et al. Minfi: a flexible and comprehensive Bioconductor package for the analysis of Infinium DNA Methylation microarrays. Bioinformatics. 2014;30:1363-9.

79. Chen Y, Lemire M, Choufani S, Butcher DT, Grafodatskaya D, Zanke BW, et al. Discovery of cross-reactive probes and polymorphic CpGs in the illumina infinium HumanMethylation450 microarray. Epigenetics. 2013;8:203-9.

80. Triche TJ, Weisenberger DJ, Van Den Berg D, Laird PW, Siegmund KD. Low-level processing of Illumina Infinium DNA Methylation BeadArrays Nucleic Acids Res. 2013;41:e90.

81. Houseman EA, Accomando WP, Koestler DC, Christensen BC, Marsit CJ, Nelson $\mathrm{HH}$, et al. DNA methylation arrays as surrogate measures of cell mixture distribution. BMC Bioinformatics. 2012;13:86.

82. Bakulski KM, Feinberg Jl, Andrews SV, Yang J, Brown S, McKenney SL, et al. DNA methylation of cord blood cell types: applications for mixed cell birth studies. Epigenetics. 2016;11:354-62.

83. Reinius LE, Acevedo N, Joerink M, Pershagen G, Dahlén SE, Greco D, et al. Differential DNA methylation in purified human blood cells: Implications for cell lineage and studies on disease susceptibility. PLOS ONE. 2012;7:e41361.

84. Ritchie M, Phipson B, Wu D, Hu Y, Law C, Shi W, et al. limma powers differential expression analyses for RNA-sequencing and microarray studies. Nucleic Acids Res. 2015;43:e47.

85. Du P, Zhang X, Huang C-C, Jafari N, Kibbe WA, Hou L, et al. Comparison of Beta-value and $\mathrm{M}$-value methods for quantifying methylation levels by microarray analysis. BMC Bioinf BioMed Central; 2010;11:587.
86. Benjamini Y, Hochberg Y. Controlling the false discovery rate: a practical and powerful approach to multiple testing. J R Stat Soc. 1995;57:289-300.

87. Pedersen BS, Schwartz DA, Yang IV, Kechris KJ. Comb-p: software for combining, analyzing, grouping and correcting spatially correlated $p$-values. Bioinformatics. 2012;28:2986-8.

88. Xu Z, Niu L, Li L, Taylor JA. ENmix: a novel background correction method for Illumina HumanMethylation450 BeadChip. Nucleic Acids Res. 2016;44:e20.

89. Maksimovic J, Oshlack A, Phipson B. Gene set enrichment analysis for genome-wide DNA methylation data. Genome Biol. 2021;22:173.

90. Phipson B, Maksimovic J, Oshlack A. missMethyl: an R package for analyzing data from Illumina's HumanMethylation450 platform. Bioinformatics. 2015:32:btv560.

91. Geeleher P, Hartnett L, Egan LJ, Golden A, Raja Ali RA, Seoighe C. Gene-set analysis is severely biased when applied to genome-wide methylation data. Bioinformatics. 2013;29:1851-7.

92. Supek F, Bošnjak M, Škunca N, Šmuc T. REVIGO summarizes and visualizes long lists of gene ontology terms. PLoS ONE. 2011;6:e21800.

93. R Core Team. R: A language and environment for statistical computing [Internet]. Vienna, Austria: R Foundation for Statistical Computing; 2015. Available from: https://www.r-project.org/

\section{Publisher's Note}

Springer Nature remains neutral with regard to jurisdictional claims in published maps and institutional affiliations.
Ready to submit your research? Choose BMC and benefit from:

- fast, convenient online submission

- thorough peer review by experienced researchers in your field

- rapid publication on acceptance

- support for research data, including large and complex data types

- gold Open Access which fosters wider collaboration and increased citations

- maximum visibility for your research: over $100 \mathrm{M}$ website views per year

At $\mathrm{BMC}$, research is always in progress.

Learn more biomedcentral.com/submissions 